\title{
Oxidation activity restoration of diesel particulate matter by aging in air
}

Jianbing Gao, ${ }^{\dagger,+* *}$ Chaochen Ma, ${ }^{\ddagger *}$ Guohong Tian, ${ }^{\dagger}$ Junyan Chen, ${ }^{\S}$ Shikai Xing,, Liyong Huang

${ }^{\dagger}$ Department of Mechanical Engineering Sciences, University of Surrey, Guildford GU2 7XH, UK

$\$$ School of Mechanical Engineering, Beijing Institute of Technology, Beijing 100081, China

${ }^{\S}$ Collage of Environmental Science and Resource, Shanxi University, Taiyuan 030006, China

"School of Vocational and Technical, Hebei Normal University, Shijiazhuang 050024, China

ABSTRACT: Diesel particulate matter (PM) was collected at different tailpipe positions where the sampling temperature was different. The PM samples were pre-treated in air at high temperature until $40 \%$ mass loss. Then, the partially oxidized PM samples were aged in air for 40 days, and the physicochemical properties of partially oxidized PM before and after aging in air were tested. The results showed that the oxidation activity of partially oxidized PM was appreciably restored by aging in air. The morphology, diameter distribution of primary particles and nanostructures of partially oxidized PM changed slightly after aging in air. The amorphous carbon adsorbing on PM surface were faintly observed through high resolution transmission electron microscope (HRTEM) images. The adsorption of oxygen-containing functional groups (carbonyl and hydroxy) and organic compounds were evidenced through Fourier transform infrared spectroscopy (FTIR) and Raman parameter $A_{D 3} / A_{G}$. The crystallite size calculated using Raman parameter decreased slightly after aging in air.

Keywords: diesel particulate matter; aging in air; oxidation activity restoration; physicochemical properties

\section{Introduction}

Diesel engines are widely used in the transportations, because of the excellent fuel economy, durability and torque ${ }^{1}$. However, particulate matter (PM) emitted by diesel engines has brought about negative effects on human health and environment ${ }^{2,3}$. Legislations limit diesel PM emissions both in mass and number that many measurements have been done to meet the legislations ${ }^{4-8}$. Diesel particulate filter (DPF) is considered to be the most successful technology and widely used. PM emitted from diesel engines is continuously captured on the filter of DPF, which causes an increasing backpressure of diesel engines and worsens the engine power and economic 
performances ${ }^{3,9}$. The captured PM has to be removed by active or passive methods to avoid excessive deterioration of engine performances ${ }^{10,11}$. The oxidation behaviours of diesel PM are necessary to achieve DPF regeneration, and the oxidation activity is closely related to physicochemical properties of diesel PM ${ }^{12-15}$. The commonly used method to test the oxidation activity is thermogravimetric analysis (TGA) experiments. High resolution transmission electron microscopy (TEM), Raman spectra, Fourier transform infrared spectroscopy (FTIR), X-ray photoelectron spectroscopy (XPS) and X-ray diffraction (XRD) were used to investigate the physicochemical properties of diesel PM ${ }^{16-20}$.

Yehliu et. al ${ }^{11}$ researched the oxidation activity of diesel soot sampled at different engine operating conditions and combustion phases. PM sampled at high engine speed showed high volatile organic compound (VOC) content and apparent rate constant. Higher engine speed meant less time for VOC to be post-oxidized in cylinder that led to higher VOC content. Oxygen-containing functional groups adhering on PM surface provided active surface for PM oxidation ${ }^{21,22}$ that caused high apparent rate constant. Yehliu et. al ${ }^{11}$ also analyzed the oxidation rates and microstructures of diesel PM generated at retarded and advanced fuel start of injection (SOI) timing. The apparent rate constant obtained from TGA experiments was 2.3 times higher for retarding SOI timing (2 crank angle degree, CAD) than advancing SOI timing (2 CAD). The diesel PM sampled from retarding SOI timing had shorter crystallite fringe length and huger tortuosity than advancing SOI timing that partly explained the high rate constant for retarding SOI timing. The conclusions were similar to Gargiulo's results ${ }^{19}$ that shorter crystallite fringe length and huger tortuosity meant higher oxidation activity of diesel soot. The crystallites arranged more orderly and densely for diesel soot with less oxidation activity that was seen from HRTEM figures ${ }^{11,14,23}$.

The crystallite size obtained using HRTEM images is similar to the results calculated using Raman spectra and XRD parameters, and they are mutual complementation ${ }^{17,24-26}$. The Raman spectra present the degree of lattice defects and carbon graphitization that show closely relations with PM oxidation activity ${ }^{4,17,27}$. However, the relations of Raman spectra parameters and oxidation activity are still in debate ${ }^{17,28,29}$. Gao et. al ${ }^{4}$ showed that the apparent rate constant at $50 \%$ mass loss increased with full width at half maximum (FWHM) of D1 band, and the average activation energy increased with FWHM of G band. Sheng et. al ${ }^{30}$ presented the results that the temperature at $20 \%$ mass loss dropped with increasing Raman parameter $A_{D I} / A_{G}$ (area ratio of $\mathrm{D} 1$ band to $\mathrm{G}$ band). The D3 band of Raman spectra is caused by amorphous carbon that mainly refers to the organic 
compounds containing oxygen-containing functional groups ${ }^{26,31,32}$. Reference ${ }^{10}$ showed that the amount of initial oxygen content was more important factor governing oxidation activity compared with initial structures and pore size distributions. The statement was demonstrated by the fact that biodiesel-derived soot was 5 times more oxidation reactive than Fischer-Tropsch (FT) diesel soot, though biodiesel-derived soot was more orderly arranged. Chien et. al ${ }^{16}$ tested oxygen-containing functional groups using FTIR technology that biodiesel soot showed high anhydride and carboxyl content that dominated oxidation activity.

Engine operation condition is variable in real-time driving so that high load causes high exhaust temperature leading to partially oxidation of diesel PM. The partially oxidized PM is exposed to low temperature atmosphere after engine stops. Exposure causes the changes of physicochemical properties, which leads to the changes of oxidation activity that shows closely related to DPF regeneration ${ }^{33}$. For the periodical DPF regeneration, it more often involves partially oxidized PM after aging rather than fresh PM. The physicochemical properties changed enormously when diesel soot was partially oxidized, and the oxidation activity decreased evidently ${ }^{4,14}$. The partially oxidized PM became hollow microstructures with void cores and orderly arranged crystallites. Reference ${ }^{34}$ indicated that oxidation activity was restored for partially oxidized PM after aging in air. Yezerets et. al ${ }^{34}$ contributed oxidation activity restoration to the changes in chemical compositions rather than microstructures, however, the reasons were only based on the speculations rather than experiment evidence. Lambe and Browne ${ }^{35,36}$ monitored chemical composition changes of soot particles after exposing in $\mathrm{OH}$ atmosphere, and active species adhering on PM surface were tested. The literature about partially oxidized PM aging in air is scarce to date, and the questions about the reasons of oxidation activity restoration remain to be addressed. In this paper, diesel PM was sampled to investigate the oxidation activity restoration by aging in air for partially oxidized PM. And physicochemical properties of partially oxidized PM before and after aging in air were analyzed to figure out the reasons of oxidation activity restoration.

\section{Experimental work}

\subsection{The test engine}

The diesel PM was generated by a small displacement diesel engine (KD186FA). The diesel engine has run for less than $100 \mathrm{~h}$. The detailed specifications of the diesel engine are shown in reference ${ }^{4}$. The diesel engine is used as the power of a generator that the speed is constant ( $3000 \mathrm{r} / \mathrm{min})$, and the engine load is adjusted by the power output of the generator. The fundamental properties of the fuel 
used in the experiments are shown in Tab. 1. The exhaust was extracted from different positions of tailpipe and PM was captured using filter. Different sampling positions meant different temperature. The distances of the exhaust valve and the sampling positions were about $0.5 \mathrm{~m}, 1.0 \mathrm{~m}$ and $2.0 \mathrm{~m}$ where the sampling temperature was $253{ }^{\circ} \mathrm{C}, 231{ }^{\circ} \mathrm{C}$ and $185{ }^{\circ} \mathrm{C}$, and the $\mathrm{PM}$ samples were designated as sample 1, sample 2 and sample 3 respectively. Different sampling temperature means different physicochemical property changes after diesel PM emitted from cylinder.

Tab. 1 Fundamental properties of the diesel fuel

\begin{tabular}{ll}
\hline Properties & Value \\
\hline Viscosity $\left(20{ }^{\circ} \mathrm{C}\right)$ & $4.1 \mathrm{~mm}^{2} / \mathrm{s}$ \\
Density & $850 \mathrm{~kg} / \mathrm{m}^{3}$ \\
Cetane number & 52 \\
S content & $0.0042 \%$ \\
H/C ratio & 0.156 \\
$50 \%$ distillation points & $290{ }^{\circ} \mathrm{C}$ \\
$95 \%$ distillation points & $340{ }^{\circ} \mathrm{C}$ \\
\hline
\end{tabular}

\subsection{Thermogravimetric analysis}

The type of TGA device is DTG-60 that was made by Shimadzu. In order to guarantee the accuracy of TGA experiments, vacant combustion were done before the experiments to eliminate the effect of residual in last experiment and the duplicate tests were made before the experiments. The three profiles of the TGA experiments performed at the same conditions were coincident, as shown in Fig. S1. In order to obtain the partially oxidized PM, all the samples were heated at $5{ }^{\circ} \mathrm{C} / \mathrm{min}$ in air atmosphere using TGA device, until $40 \%$ mass loss. Then the air was switched as $\mathrm{N}_{2}$, and the samples were cooled to ambient temperature (pre-treatment process). The aging process of partially oxidized PM was performed by exposure in air for 40 days. The partially oxidized PM samples both before and after aging were used to do the TGA experiments, that PM samples were heated from room temperature to $700{ }^{\circ} \mathrm{C}$ at $5{ }^{\circ} \mathrm{C} / \mathrm{min}$ in air atmosphere. The flow rates of the air and $\mathrm{N}_{2}$ in the experiments were both $100 \mathrm{~mL} / \mathrm{min}$.

\subsection{High resolution transmission electron microscopy}

A field emission transmission electron microscopy (TEM) was used to obtain HRTEM images. The point-to-point resolution of HRTEM images was $0.19 \mathrm{~nm}$. Suspensions of diesel PM were prepared using ultrasonic extraction methods within acetone before HRTEM experiments. A drop of 
suspension was deposited on a lacey $\mathrm{C} / \mathrm{Cu}$ TEM grid, then dried using accent light. The applied magnifications were set as $40,000 \times$ and $500,000 \times$, the figures with low magnification were used to obtain the particle diameter distributions. More than 300 particles were used for diameter statistics. Both the particles before and after aging in air were used to perform the HRTEM experiments.

\subsection{Fourier transform infrared spectroscopy}

The functional groups contained in PM can be analyzed by FTIR spectra. FTIR spectra was obtained by FTIR spectroscopy (IRAffinity-1s) made by Shimadzu. For qualitative analysis of FTIR spectra, small amount of diesel PM was blended with $\mathrm{KBr}$ powder (about 1\% PM and 99\% $\mathrm{KBr}$ ) to make the slice. Before the test, the blank experiment was done to perform the background subtraction. The spectral region of the test was $450 \mathrm{~cm}^{-1} \sim 4500 \mathrm{~cm}^{-1}$.

\subsection{Raman spectra}

Raman spectra show sensitivity to molecular structures, and Raman signals are caused by lattice vibration and sensitive to the degree of the structural disorder ${ }^{27}$. A Invia Raman spectrometer owing an Ar-ion laser source (633 nm) was used to obtain PM Raman spectra. The first order Raman spectra (Raman shift: $700 \mathrm{~cm}^{-1}$ to $2000 \mathrm{~cm}^{-1}$ ) was investigated. Raman spectra presented two bands that were corresponding to $1350 \mathrm{~cm}^{-1}$ (D band) and $1590 \mathrm{~cm}^{-1}$ ( $\mathrm{G}$ band). D and $\mathrm{G}$ bands were caused by lattice defects and graphite carbon respectively ${ }^{26}$.

\section{Results and discussion}

\subsection{Oxidation behaviours of diesel PM}

During the pre-treatment of diesel PM, the oxidation and volatilization of VOC happened. The ramp rate and gas flow rate of the TGA experiments were $5{ }^{\circ} \mathrm{C} / \mathrm{min}$ and $100 \mathrm{~mL} / \mathrm{min}$ respectively. VOC content of diesel PM sampled at different tailpipe positions was obtained from TGA profiles where PM samples were heated in $\mathrm{N}_{2}$ atmosphere. Tab. 2 shows the VOC content and characteristic temperature of raw diesel PM. As can be seen, higher sampling temperature presented less VOC adhering on diesel PM. High volatility VOC (H-VOC) and low volatility VOC (L-VOC) content differed greatly, which was consistent with Wang's results ${ }^{37}$. The influence of VOC content on PM oxidation temperature was still in debated ${ }^{9,11,38}$. Because of the differences in physicochemical properties of raw diesel PM, the pre-treatment temperature corresponding to $40 \%$ mass loss differed significantly (final pre-treatment temperature in Tab. 2). The final pre-treatment temperature was higher than $450{ }^{\circ} \mathrm{C}$ and partial oxidation happened for soot that caused the microstructure changes. No matter the sampling positions of diesel PM, the burn out temperature differed slightly, because 
PM formation condition was the same.

Tab. 2 VOC content and characteristic temperature of raw diesel PM

\begin{tabular}{|c|c|c|c|c|c|}
\hline Sample & $\begin{array}{c}\text { H-VOC (below } 200^{\circ} \mathrm{C} \text { ) } \\
/ \%\end{array}$ & $\begin{array}{c}\mathrm{L}-\operatorname{VOC}\left(200^{\circ} \mathrm{C} \sim 450^{\circ} \mathrm{C}\right) \\
/ \%\end{array}$ & $\begin{array}{l}\text { VOC } \\
/ \%\end{array}$ & $\begin{array}{l}\text { Final pre-treatment } \\
\text { temperature }{ }^{(1)} /{ }^{\circ} \mathrm{C}\end{array}$ & $\begin{array}{c}\text { Burn out } \\
\text { temperature }{ }^{(2)} \\
/{ }^{\circ} \mathrm{C}\end{array}$ \\
\hline 1 & 2.28 & 6.35 & 8.63 & 519.5 & 630.8 \\
\hline 2 & 1.75 & 6.95 & 8.70 & 529.3 & 630.7 \\
\hline 3 & 4.38 & 15.77 & 20.15 & 517.1 & 632.6 \\
\hline
\end{tabular}

(1) Temperature corresponding $40 \%$ mass loss; ${ }^{(2)}$ Temperature corresponding to $95 \%$ mass loss.

During the pre-treatment process, the oxygen-containing organic compounds were partially oxidized, and the graphitization of soot was aggregated. Less oxygen-containing organic compounds provided less active site, and the graphitization of soot decreased the oxidation activity. Fig. 1 presents the oxidation profiles of diesel PM both before and after aging for partially oxidized PM. When temperature was higher than $400{ }^{\circ} \mathrm{C}$, pre-treated PM began to oxidize. The burn out temperature (Tab. 3) was almost the same for the three pre-treated diesel PM, and the temperature decreased slightly after aging in air. Because the PM formation temperature is the same and it is more than $1000{ }^{\circ} \mathrm{C}$. After aging in air for 40 days, the physicochemical properties changed enormously that could be inferred from the TGA profiles. As can be seen, PM oxidation behaviours in the temperature range of $450{ }^{\circ} \mathrm{C} \sim 600{ }^{\circ} \mathrm{C}$ changed greatly. Oxidation activity of pre-treated PM was partially restored that the ignition temperature dropped evidently. The aged PM began to oxidize when heating temperature was higher than $250{ }^{\circ} \mathrm{C}$, however, aging in air caused slight changes for burn out temperature. The phenomenon was coincident with the results in other study ${ }^{34}$. The average activation energy of partially oxidized PM decreased by $7.84 \mathrm{~kJ} \cdot \mathrm{mol}^{-1}, 7.55 \mathrm{~kJ} \cdot \mathrm{mol}^{-1}$ and $11.08 \mathrm{~kJ} \cdot \mathrm{mol}^{-1}$ respectively after aging in air (Tab. 3). The process of activation energy calculation was based on Arrhenius equation ${ }^{1}$, and the Arrhenius plots are shown in Fig. S2. Activation energy decrease indicated partially oxidation activity restoration after aging in air. 


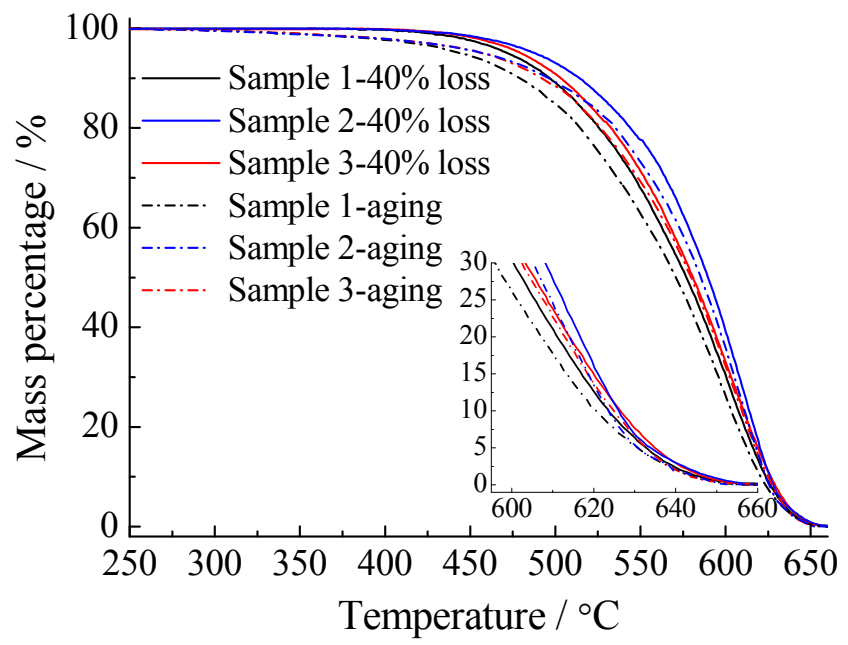

Fig. 1 Oxidation behaviours of PM before and after aging

Tab. 3 Characteristic temperature and activation energy of diesel PM

\begin{tabular}{lccccc}
\hline Sample & $T_{5 \%}$ & $T_{10 \%}$ & $T_{90 \%}$ & $T_{95 \%}$ & $\begin{array}{c}\text { Average activation } \\
\text { energy/ kJ } \cdot \mathrm{mol}^{-1}\end{array}$ \\
\hline 1-40\% loss & 472.1 & 496.5 & 623.5 & 632.6 & 136.14 \\
2-40\% loss & 488.3 & 514.2 & 626.1 & 633.8 & 145.24 \\
3-40\% loss & 480.3 & 503.1 & 626.1 & 634.9 & 175.45 \\
1-aging & 444.5 & 479.3 & 620.6 & 630.9 & 128.30 \\
2-aging & 457.7 & 496.0 & 623.6 & 630.7 & 137.69 \\
3-aging & 457.3 & 492.1 & 624.9 & 632.6 & 164.37 \\
\hline
\end{tabular}

The ignition temperature $\left(T_{5 \%}\right)$ dropped by $27.6{ }^{\circ} \mathrm{C}, 30.6{ }^{\circ} \mathrm{C}$ and $23.0^{\circ} \mathrm{C}$ respectively for the three samples after aging. The tendency of the ignition temperature drop of the three samples was inversed with $\mathrm{H}-\mathrm{VOC}$ content. And the burn out temperature change was about $2{ }^{\circ} \mathrm{C}$. Yezerets et. al ${ }^{34}$ pointed that initial oxidation activity was restored repeatedly by exposure of PM to air for weeks at room temperature, however, the oxidation activity was with no change for PM aging in He atmosphere. The restoration of oxidation activity was observed, however, the reasons causing the activity restoration was only based on speculation that some highly activity groups formed on the surface of diesel soot. Lambe et. al ${ }^{36}$ observed the chemical composition changes of organic coating after the exposure in $\mathrm{OH}$ atmosphere. The microstructure changes of diesel $\mathrm{PM}$ after aging in air is still with no report. The microstructures and compositions were investigated to further figure out the reasons of oxidation activity restoration.

\subsection{Microstructure analysis of diesel PM}


The diameter of primary diesel PM decreased and the crystallite arranged more orderly after being partially oxidized, also the microstructure change was greatly dependent on the engine conditions ${ }^{39}$. Dou et. al ${ }^{40}$ investigated the effect of the tailpipe length on particle size distribution and particle number concentration (total, nucleation and accumulation particle number). The particle size distributions moved towards to smaller diameter with increasing tailpipe length. The nucleation particle number increased rapidly with longer tailpipe length because of the condensation of L-VOC. The PM stacking degree was also related to VOC content that higher VOC content contributed to higher viscidity that partly caused the accumulation of diesel particles ${ }^{41,42}$. Fig. 2 shows the morphology of partially oxidized PM both before and after aging in air. Seriously stacked particles were observed for the three PM samples, and the periphery of these particles was overlapped. The morphology of diesel particles was almost with no changes after aging in air for 40 days (Fig. 2). Though some active species $\left(\mathrm{O}_{3}, \mathrm{NO}_{2}\right)$ existed in air, the morphology kept intact due to the low concentrations of active species and low temperature (ambient temperature).
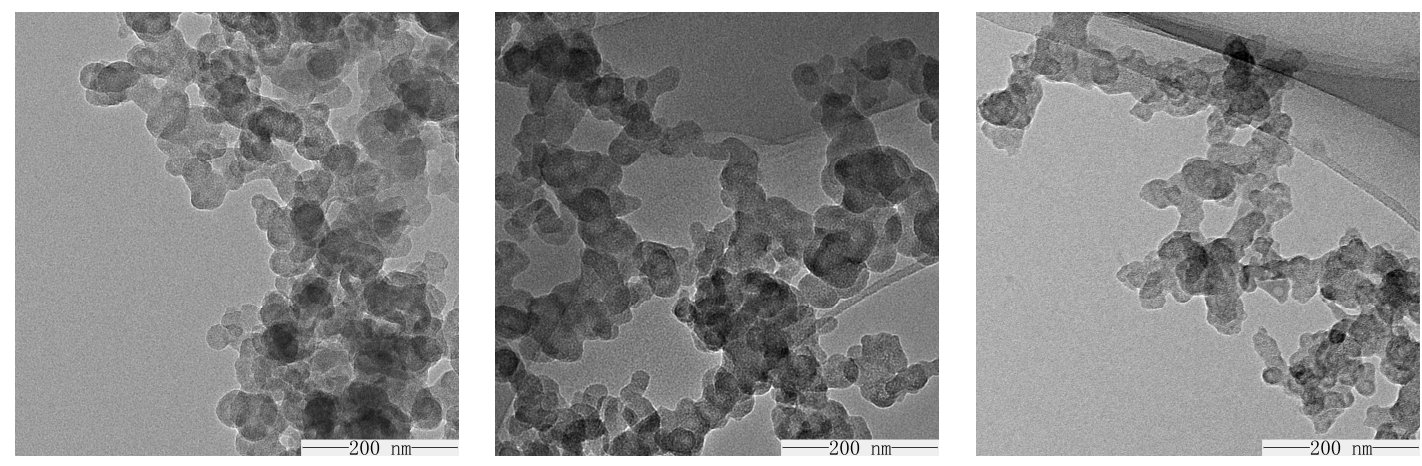

$40 \%$

loss

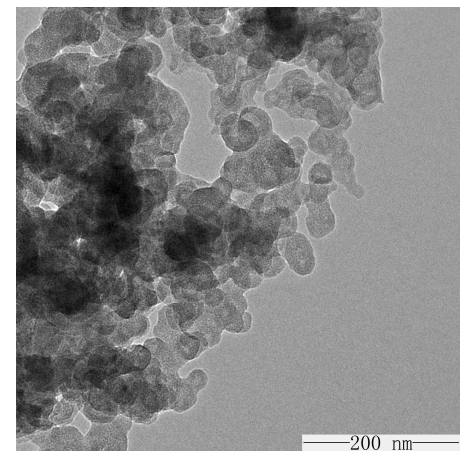

Sample 1

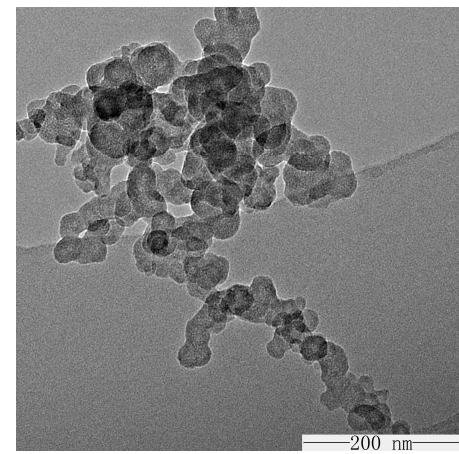

Sample 2

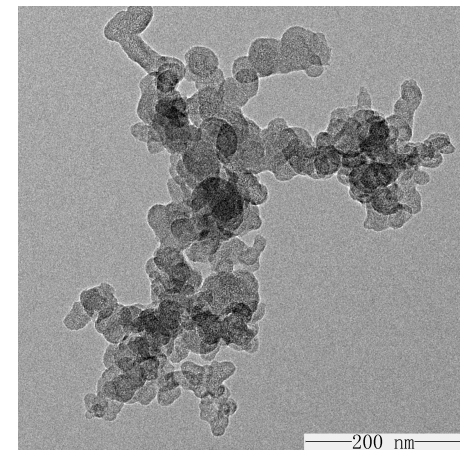

Sample 3

Fig. 2 The morphology of diesel PM both before and after aging

Diameter distributions of primary diesel PM were obtained using low resolution TEM images, as shown in Fig. 3. The number of diesel PM used for the statistics was no less than 300. The diameter distributions of partially oxidized diesel PM sampled at different tailpipe positions were similar. The peak positions of particle diameter distributions were around $30 \mathrm{~nm}$ that was slightly bigger 
than other statistic result ${ }^{3}$, and almost no particles diameter more than $80 \mathrm{~nm}$ were observed in the paper. The peak positions of partially oxidized PM after aging in air slightly shifted to right. Different from particle size distribution tested using Fast Mobility Particle Sizer (FMPS) and Electrical Low Pressure Impactor (ELPI) ${ }^{40,43}$, the nucleation and accumulation mode particles cannot be divided evidently in this paper. Primary particle diameter in this paper was geometry diameter; however, it was calculated based on aerodynamics for FMPS and ELPI. The nucleation mode particles were considered to be the inorganic salt and soluble organic fraction (SOF). The average diameter of the primary particles was almost the same for PM both before and after aging in air (Tab. 4). The chemical reaction rate was much slow during the aging in air for the partially oxidized PM. Concluded from the images of low resolution TEM and diameter distributions of primary particles, the morphology and particle diameter distributions contributed to limited oxidation activity restoration, and it seems that the burn out temperature were more dependent on PM formation conditions rather than sampling and pre-treatment conditions.
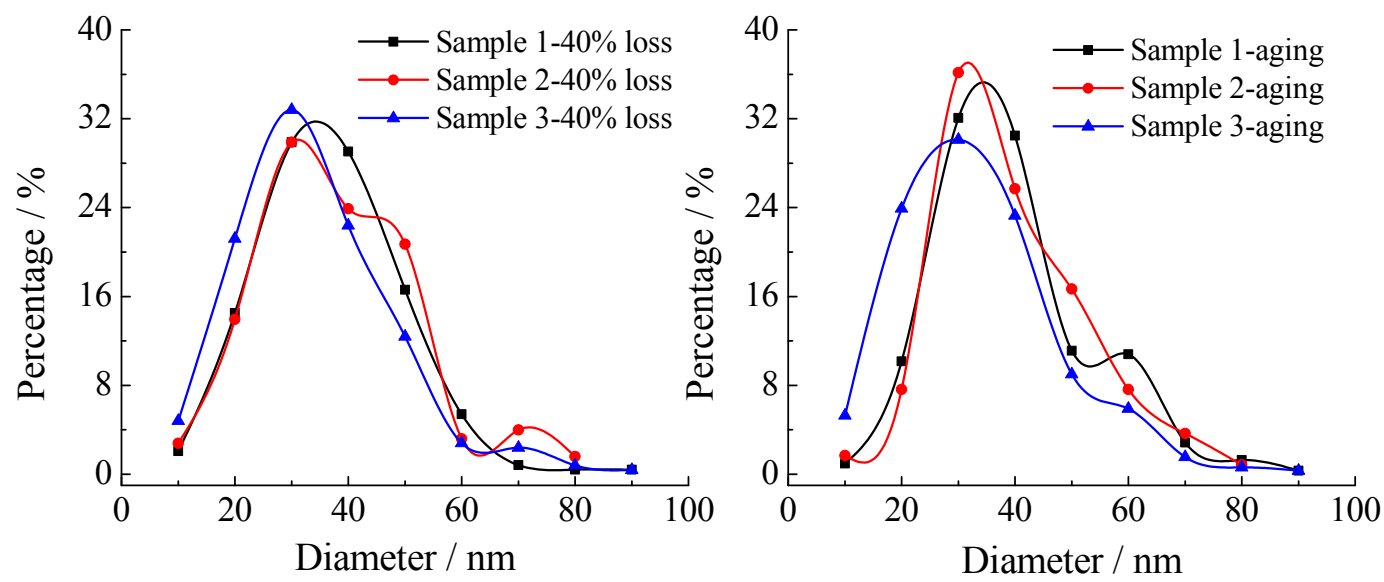

Fig. 3 Diameter distributions of primary particles

Tab. 4 Average diameter of primary particles

\begin{tabular}{lc}
\hline Sample & Average diameter $/ \mathrm{nm}$ \\
\hline $1-40 \%$ loss & 38.2 \\
$2-40 \%$ loss & 38.8 \\
3-40\% loss & 33.9 \\
1-aging & 38.5 \\
2-aging & 38.4 \\
3-aging & 33.6 \\
\hline
\end{tabular}

The crystallite arrangement showed closely related to PM oxidation activity that more densely 
arranged crystallite and longer crystallite fringe decreased oxidation activity ${ }^{39}$. Fig. 4 shows the nanostructures of diesel PM both before and after aging in air for partially oxidized PM. The partially oxidized PM presented core-shell like structures with void cores and orderly arranged crystallite. The nanostructures of partially oxidized PM were similar to other references ${ }^{14,44}$. After long time aging in air, the core-shell like structures remained unchanged and the void cores were still evident. But some amorphous carbon adhered on the periphery of primary particles after aging in air that the phenomenon was obvious for sample 2. The phenomenon was ambiguous for sample 1 and sample 3 that partly explained the maximum drop $\left(30.6^{\circ} \mathrm{C}\right)$ of ignition temperature for sample 2. References ${ }^{22,32}$ indicated that amorphous carbon were composed of oxygen-containing organic compounds that provided active sites for PM oxidation. Aging in air restored the active sites, though the sites decreased greatly after partial oxidation at high pre-treatment temperature. So that aged PM began to oxidize when temperature was around $300^{\circ} \mathrm{C}$.
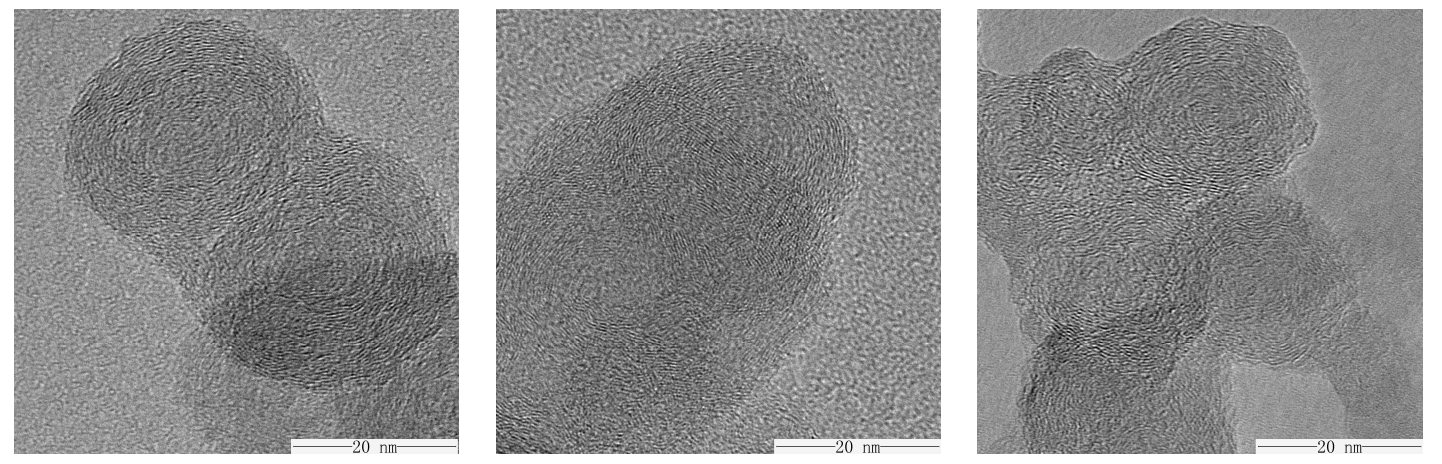

$40 \%$
loss

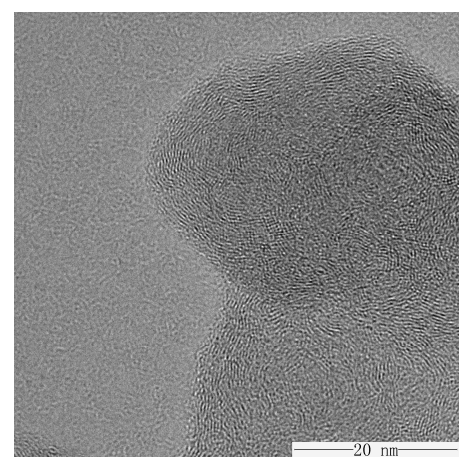

Sample 1

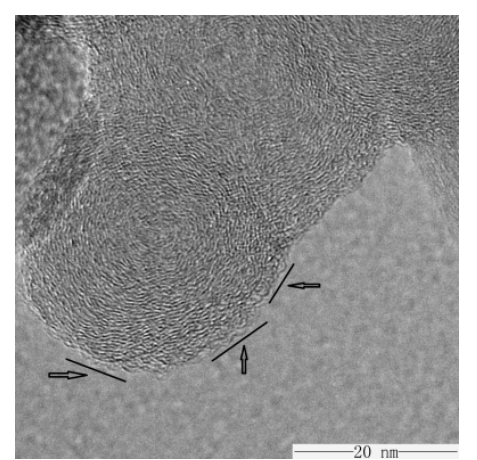

Sample 2

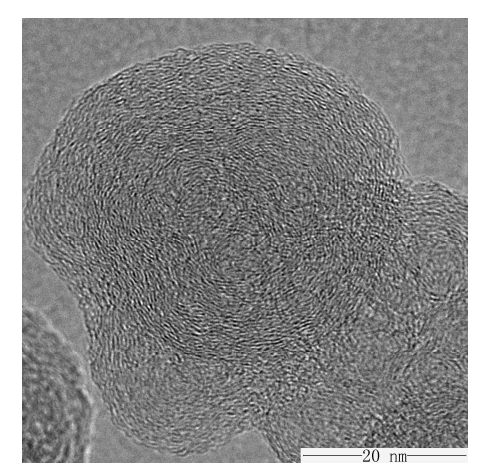

Sample 3

Fig. 4 Nanostructures of diesel PM both before and after aging

\subsection{FTIR analysis of diesel PM}

Amorphous carbon adhering on the surface of the aged PM was observed by HRTEM figures for some samples, organic compounds were further tested using FTIR. Fig. 5 shows the functional groups of partially oxidized PM after aging in air. As can be seen, the absorbance intensity of partially oxidized PM was weak. After $40 \%$ mass loss for diesel PM during the pre-treatment 
process, the organic compounds were almost breakup and oxidized. Song et. al ${ }^{45}$ tested oxygen content of diesel and biodiesel PM, the oxygen content dropped sharply when more than $40 \%$ mass was burnt off for biodiesel soot, while it was $20 \%$ mass loss for diesel soot. The oxygen content was rather low when $40 \%$ mass was burnt off for diesel soot that the phenomenon was consistent with the results in the paper that can be deduced from the absorbance intensity. Song et. al ${ }^{10}$ indicated that oxygen content was more important factor dominating oxidation activity than microstructures. This point was demonstrated by the fact that biodiesel soot was 5 times more reactive than diesel soot though biodiesel soot crystallite was more orderly arranged. For the partially oxidized diesel PM (40\% mass loss), the residue after pre-treatment was mainly the element carbon.
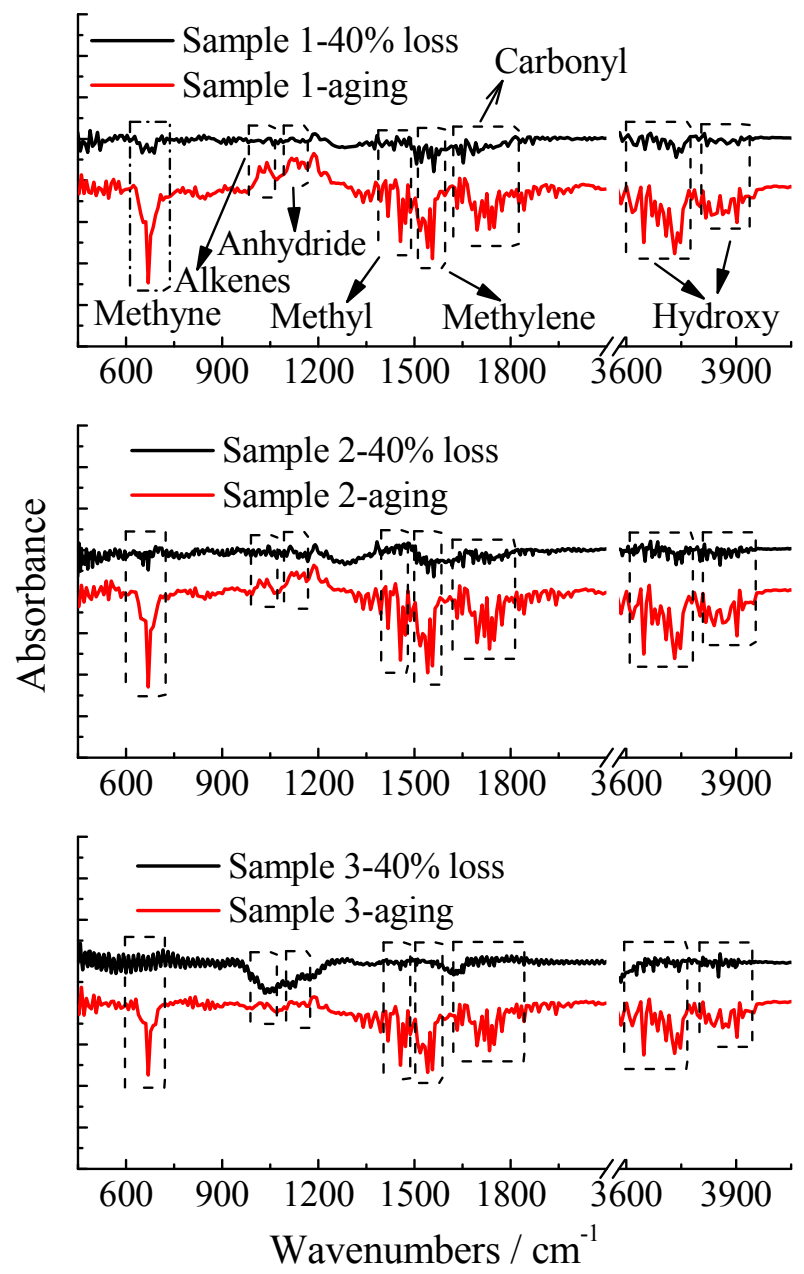

Fig. 5 FTIR spectra of diesel PM before and after aging

FTIR spectra of partially oxidized PM after aging in air for 40 days are also shown in Fig. 5. The absorbance intensity of FTIR spectra was rather strong for aged PM compared with partially oxidized PM, especially the wavenumber around $670 \mathrm{~cm}^{-1}, 1450 \mathrm{~cm}^{-1}, 1550 \mathrm{~cm}^{-1}, 1700 \mathrm{~cm}^{-1}$ and $3700 \mathrm{~cm}^{-1}$. As indicated in the figure, the organic compounds adhering on PM surface during the aging process were mainly methyl, methylene, methyne, carbonyl and hydroxy. The carbonyl 
mainly contained anhydride $\left(\sim 1810 \mathrm{~cm}^{-1}, \sim 1760 \mathrm{~cm}^{-1}\right)$, aldehydes $\left(\sim 1735 \mathrm{~cm}^{-1}\right)$, ketone $(\sim 1725$ $\left.\mathrm{cm}^{-1}\right)$, carboxylic acid $\left(\sim 1715 \mathrm{~cm}^{-1}\right)$ and amide $\left(\sim 1690 \mathrm{~cm}^{-1}\right)$. Carbonyl and hydroxy contained oxygenium which formed active sites on PM surface. These organic compounds were easy to oxidize and provided active surfaces (surface containing active sites) for oxidation activity restoration. The absorbance intensity was closely related to the content of the target compounds. The amount of adsorbed organic compounds maybe related to the concentration in atmosphere, and the specific surface area and microcellular structure of diesel PM. The changes of absorbance intensity during the aging process were the smallest for sample 3 that partly caused the smallest drop of the ignition temperature $\left(23.0^{\circ} \mathrm{C}\right)$ after aging. The ignition temperature showed closely related to PM components, while the microstructure may dominate burn out temperature.

\subsection{Raman spectra analysis of diesel PM}

Raman spectra provided information about lattice vibration, and showed sensitivity to crystallite structures and molecular structures. Raman signals showed lattice defect and the degree of graphitization. The lattice defect and graphitization presented closely related to PM oxidation activity ${ }^{4}$. Fig. 6 shows Raman spectra of diesel PM before and after aging. D band $\left(1350 \mathrm{~cm}^{-1}\right)$ was related to lattice defects in basal plane of grapheme layers, and the $\mathrm{G}$ band $\left(1580 \mathrm{~cm}^{-1}\right)$ was related to carbon graphitization. The Raman parameter $I_{D} / I_{G}$ of partially oxidized PM sampled at different tailpipe positions was different greatly, and the parameter increased then decreased with increasing tailpipe length. The parameter was closely related to engine operation conditions and fuel properties; however, the tendency was inconsistent ${ }^{3,4,46,47}$. The parameter changes of the three samples after aging in air were inconsistent that it decreased for samples 1 and 2, while it increased for sample 3.
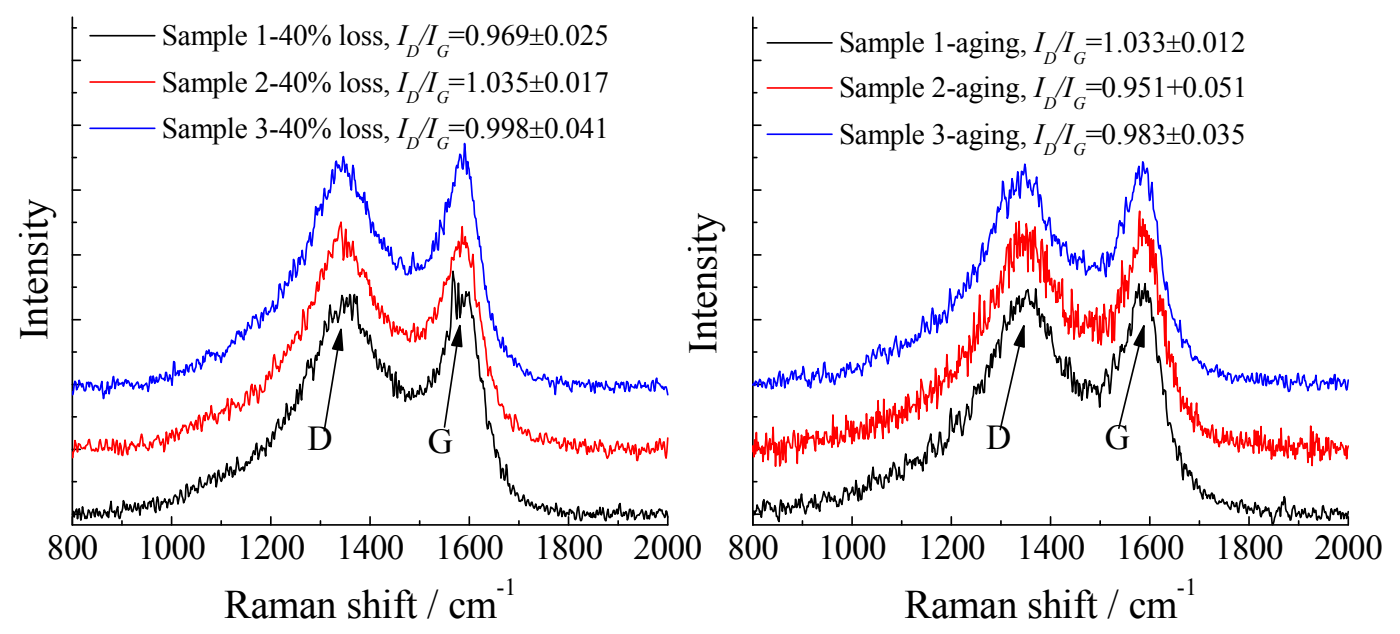

Fig. 6 Raman spectra of diesel PM both before and after aging

The two- and three-curve-fitting methods were used for the first order Raman spectra (Fig. 7), and 
the obtained Raman parameters are listed in Tab. 5 and 6. The correlation coefficients of the fitted curves were more than 0.988 . The peak positions of D1, D3 and G bands were corresponding to $1350 \mathrm{~cm}^{-1}, \sim 1500 \mathrm{~cm}^{-1}$ and $\sim 1590 \mathrm{~cm}^{-1}$ respectively. D1 and G bands were fitted using Lorentz curves, and D3 band was fitted using Gaussian curve. D1 and G bands were caused by lattice defects and graphitized carbon respectively, and D3 band was caused by amorphous carbon that was mainly referred to the oxygen-containing organic compounds. The oxygen-containing organic compounds provide active sites for PM oxidation.
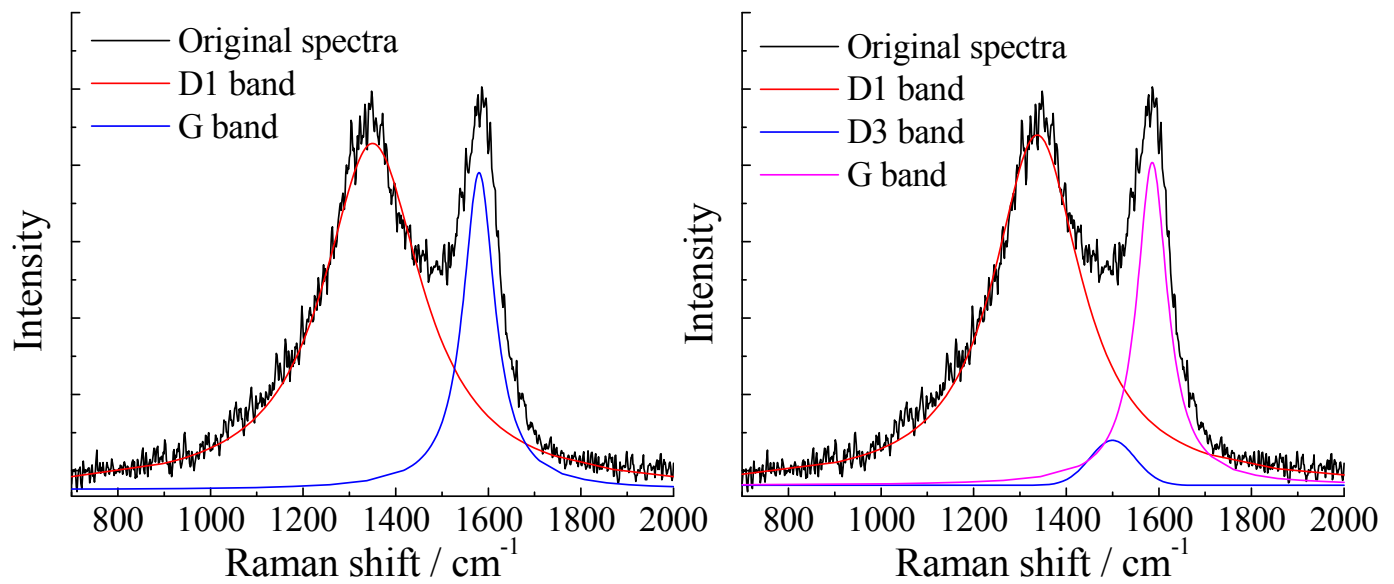

Fig. 7 The two- and three-curve-fitting methods

Tab. 5 Raman parameters obtained using two-curve-fitting methods

\begin{tabular}{lccccccc}
\hline Samples & Parameters & $1-40 \%$ loss & $2-40 \%$ loss & $3-40 \%$ loss & 1-aing & 2-aging & 3-aging \\
\hline \multirow{2}{*}{ FWHM $/ \mathrm{cm}^{-1}$} & $\mathrm{D} 1$ & $247.1 \pm 15.2$ & $240.2 \pm 9.6$ & $239.6 \pm 20.1$ & $257.1 \pm 8.9$ & $245.7 \pm 15.8$ & $259.2 \pm 23.6$ \\
& $\mathrm{G}$ & $86.6 \pm 6.8$ & $86.2 \pm 5.4$ & $81.7 \pm 3.2$ & $86.7 \pm 8.2$ & $91.4 \pm 5.9$ & $83.2 \pm 10.1$ \\
Intensity ratio & $I_{D I} / I_{G}$ & $1.07 \pm 0.13$ & $1.09 \pm 0.09$ & $1.08 \pm 0.08$ & $1.11 \pm 0.15$ & $1.10 \pm 0.06$ & $1.09 \pm 0.11$ \\
Area ratio & $A_{D I} / A_{G}$ & $3.06 \pm 0.25$ & $3.12 \pm 0.37$ & $3.16 \pm 0.16$ & $3.29 \pm 0.28$ & $2.97 \pm 0.19$ & $3.40 \pm 0.26$ \\
\hline
\end{tabular}

$I_{D I} / I_{G}$ : The intensity ratio of $\mathrm{D} 1$ band to $\mathrm{G}$ band; $A_{D I} / A_{G}$ : The area ratio of $\mathrm{D} 1$ band to $\mathrm{G}$ band.

Tab. 6 Raman parameters obtained using three-curve-fitting method

\begin{tabular}{lccccccc}
\hline Samples & Parameters & $1-40 \%$ loss & $2-40 \%$ loss & 3-40\% loss & 1-aing & 2-aging & 3-aging \\
\hline \multirow{2}{*}{$\mathrm{FWHM} \mathrm{/} \mathrm{cm}$} & $\mathrm{D} 1$ & $233.7 \pm 12.3$ & $219.7 \pm 10.8$ & $224.5 \pm 9.7$ & $236.3 \pm 17.2$ & $233.9 \pm 5.2$ & $230.7 \pm 20.3$ \\
& $\mathrm{D} 3$ & $122.0 \pm 3.6$ & $102.7 \pm 8.5$ & $110.3 \pm 7.1$ & $154.0 \pm 10.2$ & $95.8 \pm 8.3$ & $115.6 \pm 15.3$ \\
& $\mathrm{G}$ & $79.8 \pm 3.9$ & $79.9 \pm 8.2$ & $74.9 \pm 12.5$ & $79.9 \pm 10.8$ & $80.1 \pm 8.6$ & $80.1 \pm 13.4$ \\
Intensity ratio & $I_{D I} / I_{G}$ & $1.06 \pm 0.15$ & $1.08 \pm 0.08$ & $1.09 \pm 0.05$ & $1.15 \pm 0.11$ & $1.11 \pm 0.07$ & $1.12 \pm 0.06$ \\
& $I_{D 3} / I_{G}$ & $0.11 \pm 0.01$ & $0.13 \pm 0.02$ & $0.12 \pm 0.01$ & $0.15 \pm 0.03$ & $0.14 \pm 0.01$ & $0.14 \pm 0.01$ \\
Area ratio & $A_{D I} / A_{G}$ & $3.11 \pm 0.52$ & $3.02 \pm 0.31$ & $3.14 \pm 0.29$ & $3.28 \pm 0.17$ & $3.12 \pm 0.25$ & $3.13 \pm 0.41$ \\
\hline
\end{tabular}



$A_{D 3} / A_{G}$
$0.12 \pm 0.01$
$0.12 \pm 0.01$
$0.12 \pm 0.01$
$0.19 \pm 0.01$
$0.10 \pm 0.01$
$0.17 \pm 0.01$

$I_{D 3} / I_{G}$ : The intensity ratio of $\mathrm{D} 1$ band to $\mathrm{G}$ band; $A_{D 3} / A_{G}$ : The area ratio of $\mathrm{D} 1$ band to $\mathrm{G}$ band. The error of $A_{D 3} / A_{G}$ was smaller than 0.01 , that was thought to be 0.01 .

The Raman parameter changes of the three partially oxidized PM samples were similar after aging in air for 40 days. The intensity ratio $I_{D 1} / I_{G}$ increased after aging that indicated that the defects of diesel PM increased and the graphitization decreased. The FWHM decrease of D1 band and the increase for $\mathrm{G}$ band meant that the anisotropy drop of the defect carbons, while the anisotropy of the graphitized carbon increased. That partially led to the oxidation activity restoration. G band FWHM and $I_{D I} / I_{G}$ decreased with increasing soot formation temperature ${ }^{30}$ that the oxidation activity showed positive correlations to G band FWHM and $I_{D I} / I_{G}$. The result was consistent with the phenomenon in this paper. The increase of Raman parameter $I_{D 3} / I_{G}$ demonstrated that the oxygen-containing organic compounds increased after aging. Aging in air caused additional amorphous carbon, which partially caused oxidation activity restoration. The results were agreed with FTIR spectra. The increased oxygen-containing functional groups restored the active sites for PM oxidation.

The Raman parameters and HRTEM results are mutually complementary in calculating crystallite size. The crystallite size $L_{a}$ could be calculated using the Knight and White equation, as shown in Equations (1) ${ }^{26}$. The crystallite size is inversely correlated to Raman parameters $I_{D 1} / I_{G}$. Raman parameters were obtained using three-curve-fitting method, as listed in Tab. 6. The crystallite size calculated using intensity ratio $I_{D I} / I_{G}$ is shown in Fig. 8. The crystallite size decreased slightly after aging in air, which was caused by the decrease of $I_{D I} / I_{G}$. The decreased crystallite size also partially contributed to the oxidation activity restoration of partially oxidized PM.

$$
L_{a}=4.4\left(I_{D I} / I_{G}\right)^{-1}
$$

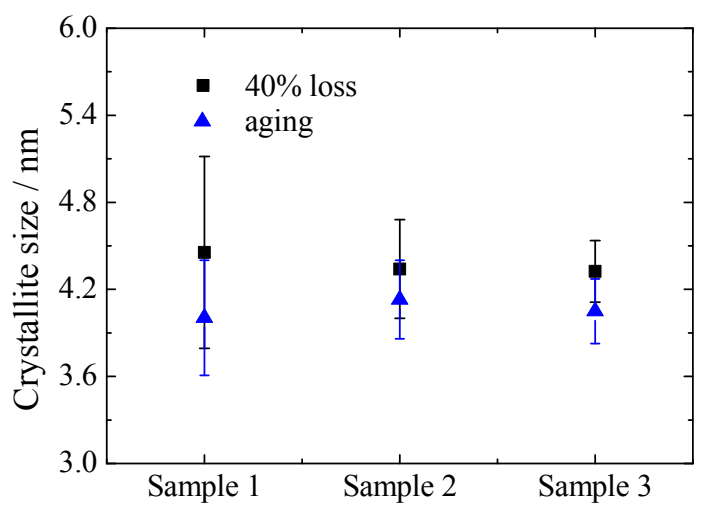

Fig. 8 Crystallite size based on Raman parameter 


\section{Conclusions}

Diesel PM was sampled at different tailpipe positions where the temperature differed greatly. In order to investigate the oxidation activity restoration, the partially oxidized PM ( $40 \%$ mass loss) was aged in air. The oxidation activity was tested by TGA experiments, and the physiochemical properties of partially oxidized diesel PM both before and after aging were obtained using the HRTEM, FTIR and Raman spectra. The obtained conclusions were as the following:

(1) The oxidation activity of oxidized PM was partially restored by aging in air. The ignition temperature of the partially oxidized PM dropped by $27.6{ }^{\circ} \mathrm{C}, 30.6{ }^{\circ} \mathrm{C}$ and $23.0^{\circ} \mathrm{C}$ respectively for the diesel PM sampled at different tailpipe positions. The burn out temperature drop was limited after aging in air that it was around $2{ }^{\circ} \mathrm{C}$.

(2) The morphology and the average diameter of diesel PM before and after aging changed slightly. Some amorphous carbon adhering on the periphery of the primary particles was observed for some diesel PM.

(3) The adsorption of some oxygen functional groups (carbonyl and hydroxy) and organic compounds (methyne, methyl, methylene, alkenes and anhydride) on the surface of the partially oxidized PM were tested though FTIR device. The adsorbate provided active sites for partially oxidized PM, and the adsorbate dominated oxidation activity restoration.

(4) Raman parameters were obtained to indicate the lattice defects and carbon graphitization. Aging in the air caused more seriously crystallite defects and less carbon graphitization. The oxygen-containing functional groups of diesel PM increased after long time aging in the air. The crystallite size of aged PM calculated based on Raman parameter $I_{D I} / I_{G}$ decreased compared with PM before aging.

\section{Supplementary information}

Provide the information of duplicate tests of TGA experiments and Arrhenius plots.

\section{Corresponding author:}

* E-mail: redonggaojianbing@163.com (Jianbing Gao)

machaochen1900@163.com(Chaochen Ma)

\section{Acknowledgements}

The authors acknowledge School of Chemistry, Beijing Institute of Technology did the experiments. The work was supported by Science and Technology Planning Project of Hebei Province, China 
(No. 15273703D)

\section{References}

1. Sharma, H. N.; Pahalagedara, L.; Joshi, A.; Suib, S. L.; Mhadeshwar, A. B., Experimental study of carbon black and diesel engine soot oxidation kinetics using thermogravimetric analysis. Energy \& Fuels 2012, 26, (9), 5613-5625.

2. Gao, J.; Ma, C.; Xing, S.; Zhang, Y.; Liu, J.; Feng, H., Particle-and gas-phase PAHs toxicity equivalency quantity emitted by a non-road diesel engine with non-thermal plasma technology. Environmental Science and Pollution Research 2016, 23, (19), 20017-20026.

3. Mühlbauer, W.; Zöllner, C.; Lehmann, S.; Lorenz, S.; Brüggemann, D., Correlations between physicochemical properties of emitted diesel particulate matter and its reactivity. Combustion and Flame 2016, 167, 39-51.

4. Gao, J.; Ma, C.; Xia, F.; Xing, S.; Sun, L.; Huang, L., Raman characteristics of PM emitted by a diesel engine equipped with a NTP reactor. Fuel 2016, 185, 289-297.

5. Ma, C.; Gao, J.; Zhong, L.; Xing, S., Experimental investigation of the oxidation behaviour and thermal kinetics of diesel particulate matter with non-thermal plasma. Applied Thermal Engineering 2016, 99, 1110-1118.

6. Monirul, I.; Masjuki, H.; Kalam, M.; Mosarof, M.; Zulkifli, N.; Teoh, Y.; How, H., Assessment of performance, emission and combustion characteristics of palm, jatropha and Calophyllum inophyllum biodiesel blends. Fuel 2016, 181, 985-995.

7. Zheng, Z.; Wang, X.; Zhong, X.; Hu, B.; Liu, H.; Yao, M., Experimental study on the combustion and emissions fueling biodiesel/n-butanol, biodiesel/ethanol and biodiesel/2, 5-dimethylfuran on a diesel engine. Energy 2016, 115, 539-549.

8. Gao, J.; Ma, C.; Xing, S.; Sun, L.; Liu, J., Polycyclic aromatic hydrocarbon emissions of non-road diesel engine treated with non-thermal plasma technology. Korean Journal of Chemical Engineering 2016, 33, (12), 3425-3433.

9. Meng, Z.; Yang, D.; Yan, Y., Study of carbon black oxidation behavior under different heating rates. Journal of Thermal Analysis and Calorimetry 2014, 118, (1), 551-559.

10. Song, J.; Alam, M.; BOEHMAN*, A. L., Impact of alternative fuels on soot properties and DPF regeneration. Combustion Science and Technology 2007, 179, (9), 1991-2037.

11. Yehliu, K.; Armas, O.; Vander Wal, R. L.; Boehman, A. L., Impact of engine operating modes and combustion phasing on the reactivity of diesel soot. Combustion and Flame 2013, 160, (3), 682-691.

12. Arnal, C.; Esarte, C.; Abián, M.; Millera, A.; Bilbao, R.; Alzueta, M. U., Characterization and reactivity of soots obtained under different combustion conditions. Chem Eng Trans 2010, 22, 251-256.

13. Liati, A.; Eggenschwiler, P. D.; Gubler, E. M.; Schreiber, D.; Aguirre, M., Investigation of diesel ash particulate matter: A scanning electron microscope and transmission electron microscope study. Atmospheric Environment 2012, 49, 391-402.

14. Jaramillo, I. C.; Gaddam, C. K.; Vander Wal, R. L.; Lighty, J. S., Effect of nanostructure, oxidative pressure and extent of oxidation on model carbon reactivity. Combustion and Flame 2015, 162, (5), 1848-1856.

15. Gao, J.; Ma, C.; Xing, S.; Sun, L., Oxidation behaviours of particulate matter emitted by a diesel engine equipped with a NTP device. Applied Thermal Engineering 2017, 119, 593-602.

16. Chien, Y.-C.; Lu, M.; Chai, M.; Boreo, F. J., Characterization of biodiesel and biodiesel particulate matter by TG, TG- MS, and FTIR. Energy \& Fuels 2008, 23, (1), 202-206. 
17. Pawlyta, M.; Rouzaud, J.-N.; Duber, S., Raman microspectroscopy characterization of carbon blacks: spectral analysis and structural information. Carbon 2015, 84, 479-490.

18. Wo, H.; Dearn, K. D.; Song, R.; Hu, E.; Xu, Y.; Hu, X., Morphology, composition, and structure of carbon deposits from diesel and biomass oil/diesel blends on a pintle-type fuel injector nozzle. Tribology International 2015, 91, 189-196.

19. Gargiulo, V.; Alfè, M.; Di Blasio, G.; Beatrice, C., Chemico-physical features of soot emitted from a dual-fuel ethanol-diesel system. Fuel 2015, 150, 154-161.

20. Omidvarborna, H.; Kumar, A.; Kim, D.-S., Variation of diesel soot characteristics by different types and blends of biodiesel in a laboratory combustion chamber. Science of the Total Environment 2016, 544, 450-459.

21. Agudelo, J. R.; Álvarez, A.; Armas, O., Impact of crude vegetable oils on the oxidation reactivity and nanostructure of diesel particulate matter. Combustion and Flame 2014, 161, (11), 2904-2915.

22. Liati, A.; Spiteri, A.; Eggenschwiler, P. D.; Vogel-Schäuble, N., Microscopic investigation of soot and ash particulate matter derived from biofuel and diesel: implications for the reactivity of soot. Journal of Nanoparticle Research 2012, 14, (11), 1-18.

23. Vander Wal, R. L.; Yezerets, A.; Currier, N. W.; Kim, D. H.; Wang, C. M., HRTEM Study of diesel soot collected from diesel particulate filters. Carbon 2007, 45, (1), 70-77.

24. Olivier, B.; Bruno, G.; Jean-Pierre, P.; Emmanuel, F.; Myriam, M.; Jean-No?L, R., On the characterization of disordered and heterogeneous carbonaceous materials by Raman spectroscopy. Spectrochimica Acta Part A Molecular \& Biomolecular Spectroscopy 2003, 59, (10), 2267-2276.

25. Cancado, L. G.; Takai, K.; Enoki, T.; Endo, M., General equation for the determination of the crystallite size L a of nanographite by Raman spectroscopy. Applied Physics Letters 2006, 88, (16), 163106-163106-3.

26. Seong, H. J.; Boehman, A. L., Evaluation of raman parameters using visible raman microscopy for soot oxidative reactivity. Energy \& Fuels 2013, 27, (3), 1613-1624.

27. Sadezky, A.; Muckenhuber, H.; Grothe, H.; Niessner, R.; Pöschl, U., Raman microspectroscopy of soot and related carbonaceous materials: Spectral analysis and structural information. Carbon 2005, 43, (8), 1731-1742.

28. Ferrari, A. C., Raman spectroscopy of graphene and graphite: disorder, electron-phonon coupling, doping and nonadiabatic effects. Solid state communications 2007, 143, (1), 47-57.

29. Knauer, M.; Carrara, M.; Rothe, D.; Niessner, R.; Ivleva, N. P., Changes in Structure and Reactivity of Soot during Oxidation and Gasification by Oxygen, Studied by Micro-Raman Spectroscopy and Temperature Programmed Oxidation. Aerosol Science \& Technology 2009, 43, (1), $1-8$.

30. Sheng, C., Char structure characterised by Raman spectroscopy and its correlations with combustion reactivity. Fuel 2007, 86, (15), 2316-2324.

31. Ji, Z.; Dai, R.; Zhang, Z., Characterization of fine particulate matter in ambient air by combining TEM and multiple spectroscopic techniques-NMR, FTIR and Raman spectroscopy. Environmental Science: Processes \& Impacts 2015, 17, (3), 552-560.

32. Patel, M.; Ricardo, C. L. A.; Scardi, P.; Aswath, P. B., Morphology, structure and chemistry of extracted diesel soot-Part I: Transmission electron microscopy, Raman spectroscopy, X-ray photoelectron spectroscopy and synchrotron X-ray diffraction study. Tribology International 2012, 52, (3), 29-39.

33. Gao, J.; Ma, C.; Xing, S.; Sun, L.; Huang, L., A review of fundamental factors affecting diesel PM oxidation behaviors. Science China Technological Sciences 2017, 1-16. 
34. Yezerets, A.; Currier, N. W.; Eadler, H. A.; Suresh, A.; Madden, P. F.; Branigin, M. A., Investigation of the oxidation behavior of diesel particulate matter. Catalysis today 2003, 88, (1), 17-25.

35. Browne, E. C.; Franklin, J. P.; Canagaratna, M. R.; Massoli, P.; Kirchstetter, T. W.; Worsnop, D. R.; Wilson, K. R.; Kroll, J. H., Changes to the Chemical Composition of Soot from Heterogeneous Oxidation Reactions. The Journal of Physical Chemistry A 2015, 119, (7), 1154-1163.

36. Lambe, A.; Ahern, A.; Wright, J.; Croasdale, D.; Davidovits, P.; Onasch, T., Oxidative aging and cloud condensation nuclei activation of laboratory combustion soot. Journal of Aerosol Science 2015, 79, 31-39.

37. Wang, C.; Xu, H.; Herreros, J. M.; Lattimore, T.; Shuai, S., Fuel effect on particulate matter composition and soot oxidation in a direct-injection spark ignition (DISI) engine. Energy \& Fuels 2014, 28, (3), 2003-2012.

38. Stratakis, G.; Stamatelos, A., Thermogravimetric analysis of soot emitted by a modern diesel engine run on catalyst-doped fuel. Combustion and Flame 2003, 132, (1), 157-169.

39. Gao, J.; Ma, C.; Xing, S.; Sun, L.; Huang, L., Nanostructure analysis of particulate matter emitted from a diesel engine equipped with a NTP reactor. Fuel 2017, 192, 35-44.

40. Dou, Z.; Yao, C.; Wei, H.; Wang, B.; Liu, M.; Chen, C.; Gao, J.; Shi, J., Experimental study of the effect of engine parameters on ultrafine particle in diesel/methanol dual fuel engine. Fuel 2017, $192,45-52$.

41. Zhao, X.; Du, J.; Zhang, D.; Yuan, Y., Research on emission particle microscopic characteristics of bio-diesel / diesel engine. Journal of Guangxi University ( National Science Edition-in chinese) 2016, 41, (2), 419-425.

42. Qu, L.; Wang, Z.; Zhang, J., Influence of waste cooking oil biodiesel on oxidation reactivity and nanostructure of particulate matter from diesel engine. Fuel 2016, 181, 389-395.

43. Zhang, Z.-H.; Balasubramanian, R., Investigation of particulate emission characteristics of a diesel engine fueled with higher alcohols/biodiesel blends. Applied Energy 2016, 163, 71-80.

44. Jaramillo, I. C.; Gaddam, C. K.; Vander Wal, R. L.; Huang, C.-H.; Levinthal, J. D.; Lighty, J. S., Soot oxidation kinetics under pressurized conditions. Combustion and Flame 2014, 161, (11), 2951-2965.

45. Song, J.; Alam, M.; Boehman, A. L.; Kim, U., Examination of the oxidation behavior of biodiesel soot. Combustion and Flame 2006, 146, (4), 589-604.

46. Sharma, V.; Uy, D.; Gangopadhyay, A.; O’Neill, A.; Paxton, W. A.; Sammut, A.; Ford, M. A.; Aswath, P. B., Structure and chemistry of crankcase and exhaust soot extracted from diesel engines. Carbon 2016, 103, 327-338.

47. Ess, M. N.; Bladt, H.; Mühlbauer, W.; Seher, S. I.; Zöllner, C.; Lorenz, S.; Brüggemann, D.; Nieken, U.; Ivleva, N. P.; Niessner, R., Reactivity and structure of soot generated at varying biofuel content and engine operating parameters. Combustion and Flame 2016, 163, 157-169. 